\title{
Supporting Information: Electrochemical Sensing of Perfluorooctanesulfonate (PFOS) Using Ambient Oxygen in River Water
}

\author{
Rebecca B. Clark ${ }^{\mathrm{a}}$, Jeffrey E. Dick ${ }^{\mathrm{a}, \mathrm{b}, *}$ \\ *Corresponding Author: jedick@email.unc.edu

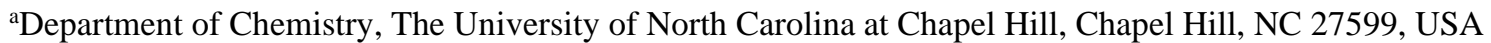 \\ ${ }^{b}$ Lineberger Comprehensive Cancer Center, School of Medicine, The University of North Carolina at Chapel Hill, \\ Chapel Hill, NC 27599, USA
}

\begin{tabular}{|c|c|}
\hline Table of Contents & Page \\
\hline Map of River Water Sample Site (Figure S1) & $\mathrm{S}-2$ \\
\hline $\begin{array}{l}\text { Differential Pulse Voltammograms of Oxygen Reduction on Various Electrode Materials } \\
\text { (Figure S2) }\end{array}$ & S-3 \\
\hline Calibration Curve and Isotherm in PBS using Differential Pulse Voltammetry (Figure S3) & S-4 \\
\hline PBS Differential Pulse Voltammograms (Figure S4) & S-5 \\
\hline Shouldering in PBS Differential Pulse Voltammograms (Figure S5) & S-6 \\
\hline $\begin{array}{l}\text { Differential Pulse Voltammogram in Haw River Water where Current was Recorded (Figure } \\
\text { S6) }\end{array}$ & S-7 \\
\hline Calibration Curves Normalized by $i_{0}-i$ in PBS and Haw River Water (Figure S7) & S-8 \\
\hline Zoomed in Nyquist Plots with Simulated Data in Haw River Water (Figure S8) & S-9 \\
\hline $\begin{array}{l}\text { Details on Brown-Forsythe and Welch's ANOVA Tests for Adsorption of PFOS on Bare } \\
\text { Glassy Carbon Electrodes (Table S1) }\end{array}$ & S-10 \\
\hline $\begin{array}{l}\text { Details on Brown-Forsythe and Welch's ANOVA Tests for Calibration Curves Made with } \\
\text { DPV in PBS (Table S2) }\end{array}$ & S-11 \\
\hline $\begin{array}{l}\text { Details on Brown-Forsythe and Welch's ANOVA Tests for Calibration Curves Made with } \\
\text { DPV in Haw River Water (Table S3) }\end{array}$ & S-12 \\
\hline $\begin{array}{l}\text { Details on Brown-Forsythe and Welch's ANOVA Tests for Calibration Curves Made with } \\
\text { EIS in Haw River Water (Table S4) }\end{array}$ & S-13 \\
\hline $\begin{array}{l}\text { Details on Brown-Forsythe and Welch's ANOVA Tests for Interference of Humic Acid and } \\
\text { Sodium Chloride (Table S5) }\end{array}$ & S-14 \\
\hline
\end{tabular}




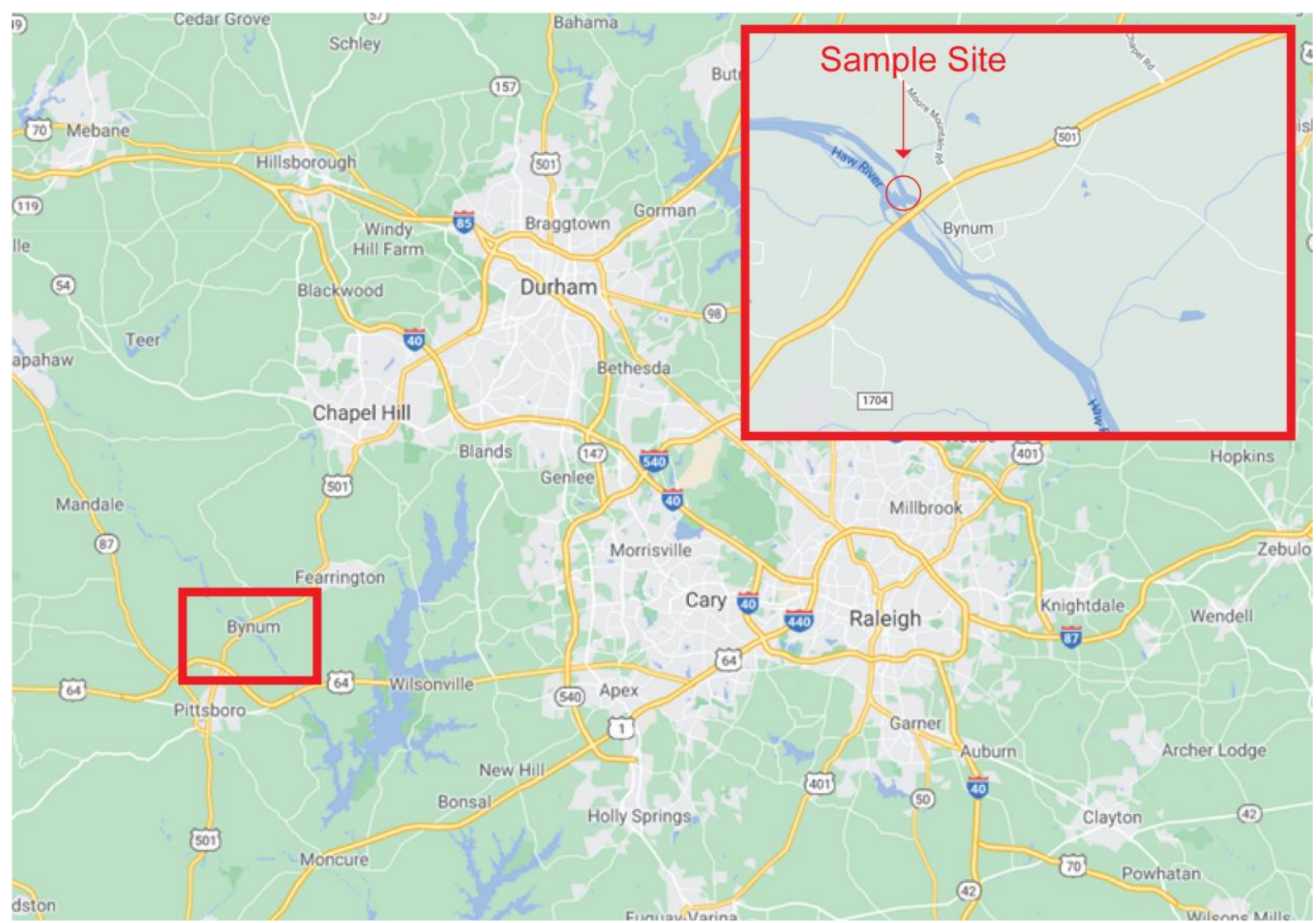

Figure S1. Sampling Site for Haw River Water $\left(35.77585654738046^{\circ},-79.1467275350264^{\circ}\right.$ latitude, longitude) 

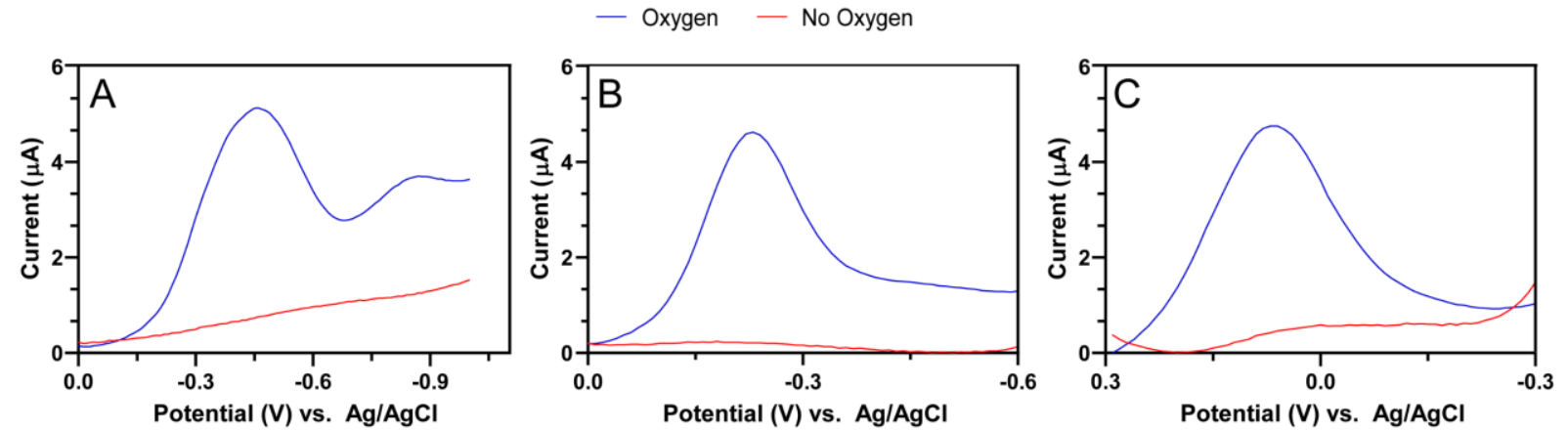

Figure S2. Differential pulse voltammograms of oxygen reduction on various electrode materials (A) glassy carbon macroelectrode $(r=1.5 \mathrm{~mm})$ (B) gold macroelectrode $(r=1 \mathrm{~mm})$ (C) platinum macroelectrode $(r=1 \mathrm{~mm})$ in the presence of oxygen and in the absence of oxygen, after bubbling with Argon gas for 20 minutes. $\mathrm{A} \mathrm{Ag} / \mathrm{AgCl}$ reference electrode and a carbon rod counter electrode were used. 

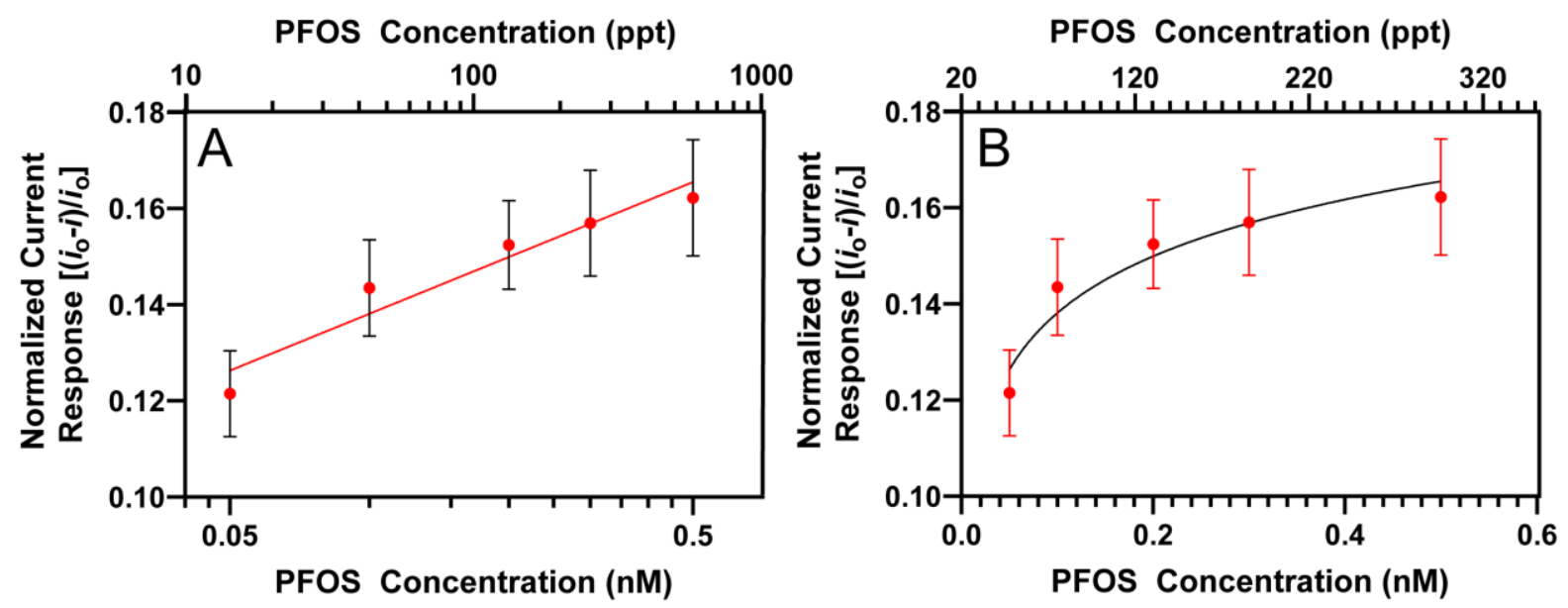

Figure S3. (A) Calibration curve in PBS illustrating the dependence of the normalized current response, $\frac{\left(i_{0}-i\right)}{i_{0}}$, on the natural $\log$ of the concentration of PFOS with the $\mathrm{x}$-axis on a logarithmic scale. The equation of the best fit line and $R^{2}$ value are $y=(0.017 \pm 0.001) \ln (x)+(0.18 \pm 0.01)$ and $R^{2}=$ 0.9326, respectively. (B) The associated isotherm for the calibration curve shown in panel A, but without a logarithmic scale on the $\mathrm{x}$-axis. The equations are $\mathrm{R}^{2}$ values are the same. All DPVs were taken using a MIP-modified glassy carbon macroelectrode, were baseline corrected, and the current response was recorded at $-0.47 \mathrm{~V}$ vs. $\mathrm{Ag} / \mathrm{AgCl}$. 


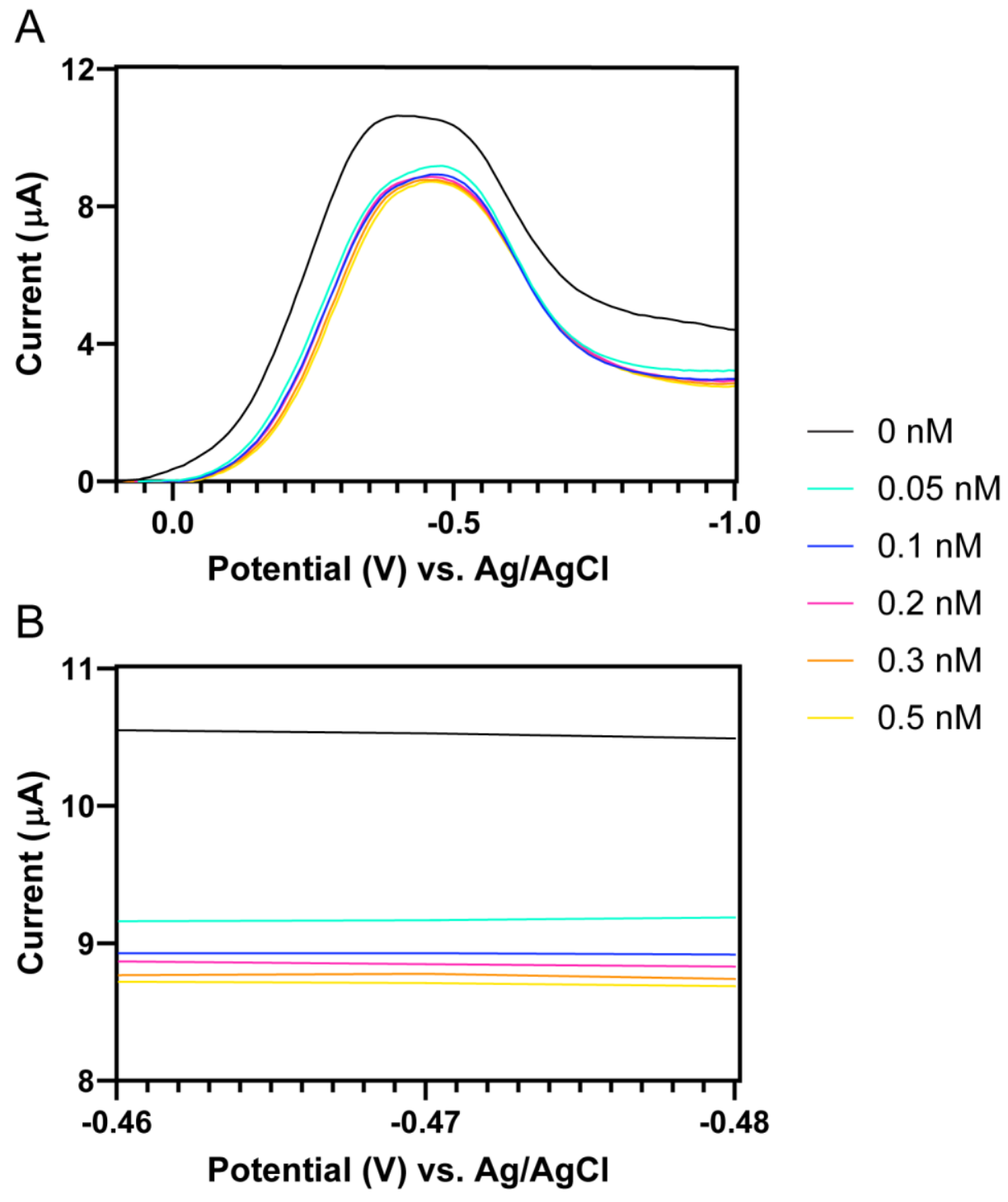

Figure S4. (A) DPV response in PBS showing a decrease in current for the reduction of oxygen caused by the blocking of active surface sites on the MIP-modified electrode due to increasing concentrations of PFOS. (B) Zoomed in view of the DPV response where the current was recorded at $-0.47 \mathrm{~V}$. A MIP-modified glassy carbon macroelectrode, carbon rod, and $\mathrm{Ag} / \mathrm{AgCl}$ electrode were used as the working, counter, and reference electrode, respectively. All DPVs were baseline corrected, and the current response was recorded at $-0.47 \mathrm{~V}$ vs. $\mathrm{Ag} / \mathrm{AgCl}$. 


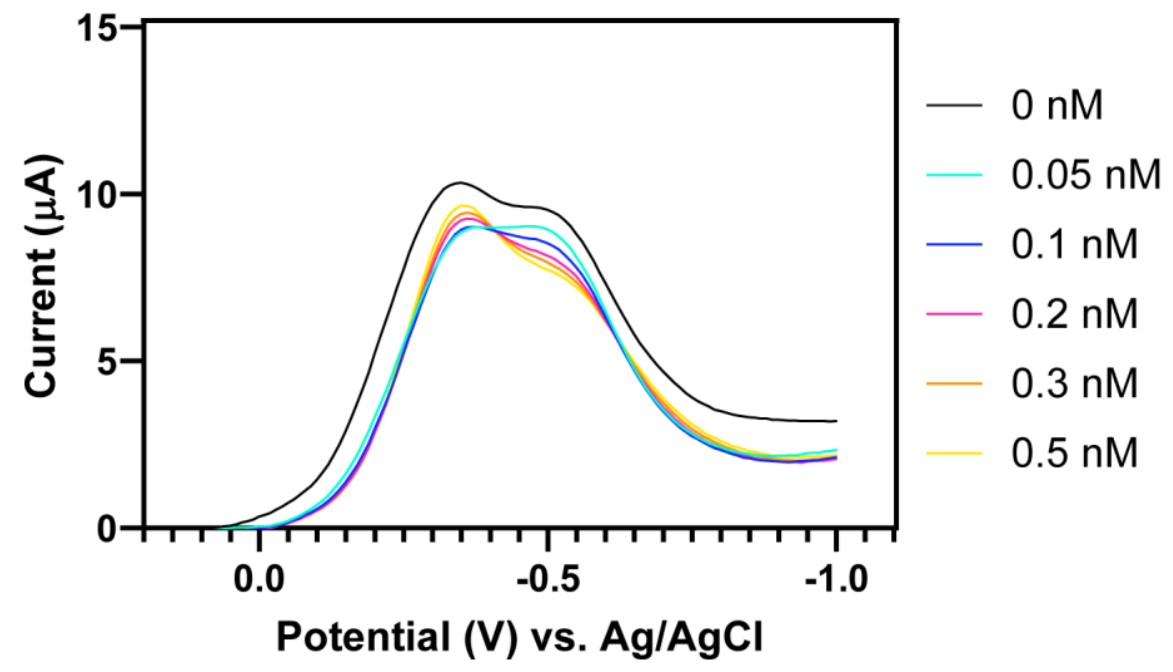

Figure S5. DPV response in PBS showing increasing peak shifting and shouldering as the concentration of PFOS increases. A MIP-modified glassy carbon macroelectrode, carbon rod, and $\mathrm{Ag} / \mathrm{AgCl}$ electrode were used as the working, counter, and reference electrode, respectively. All DPVs were baseline corrected. 


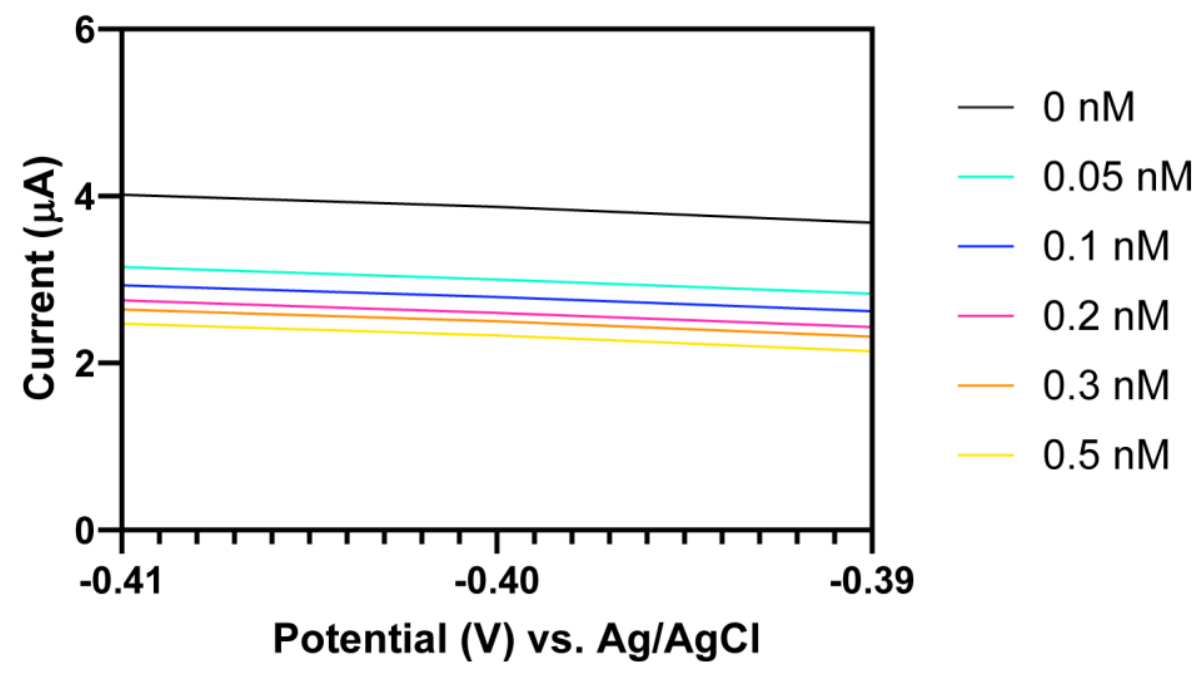

Figure S6. Zoomed in DPV response, where current was recorded in Haw River water showing a decrease in current for the reduction of oxygen caused by the blocking of active surface sites on the MIP-modified electrode due to increasing concentrations of PFOS. A MIP-modified glassy carbon macroelectrode, carbon rod, and $\mathrm{Ag} / \mathrm{AgCl}$ electrode were used as the working, counter, and reference electrode, respectively. All DPVs were baseline corrected, and the current response was recorded at $-0.40 \mathrm{~V}$ vs. $\mathrm{Ag} / \mathrm{AgCl}$. 

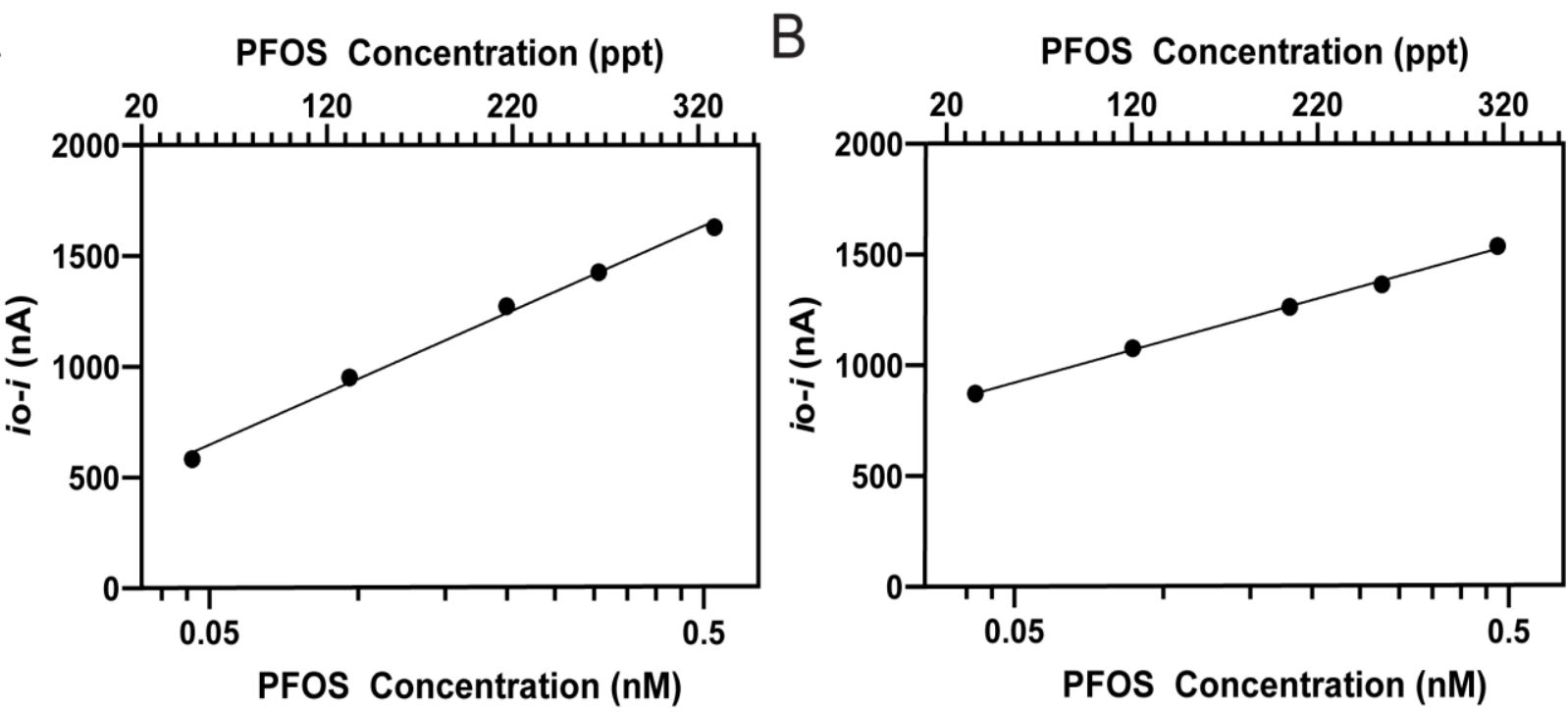

Figure S7. (A) Calibration curve in PBS illustrating the dependence of the adjusted current response $\left(i_{\mathrm{o}}-i\right)$ on the natural $\log$ of the concentration of PFOS. The equation of best fit was $\mathrm{y}=453.57 \ln (\mathrm{x})+1972.7$ and $\mathrm{R}^{2}=0.9953$. (B) Calibration curve in Haw River Water illustrating the dependence of the adjusted current response $\left(i_{0}-i\right)$ on the natural $\log$ of the concentration of PFOS. The equation of best fit was $\mathrm{y}=$ $284.02 \ln (\mathrm{x})+1724$ and $\mathrm{R}^{2}=0.9982$. A MIP-modified glassy carbon macroelectrode, carbon rod, and $\mathrm{Ag} / \mathrm{AgCl}$ electrode were used as the working, counter, and reference electrode, respectively. $\mathrm{N}=1$ sensor. 


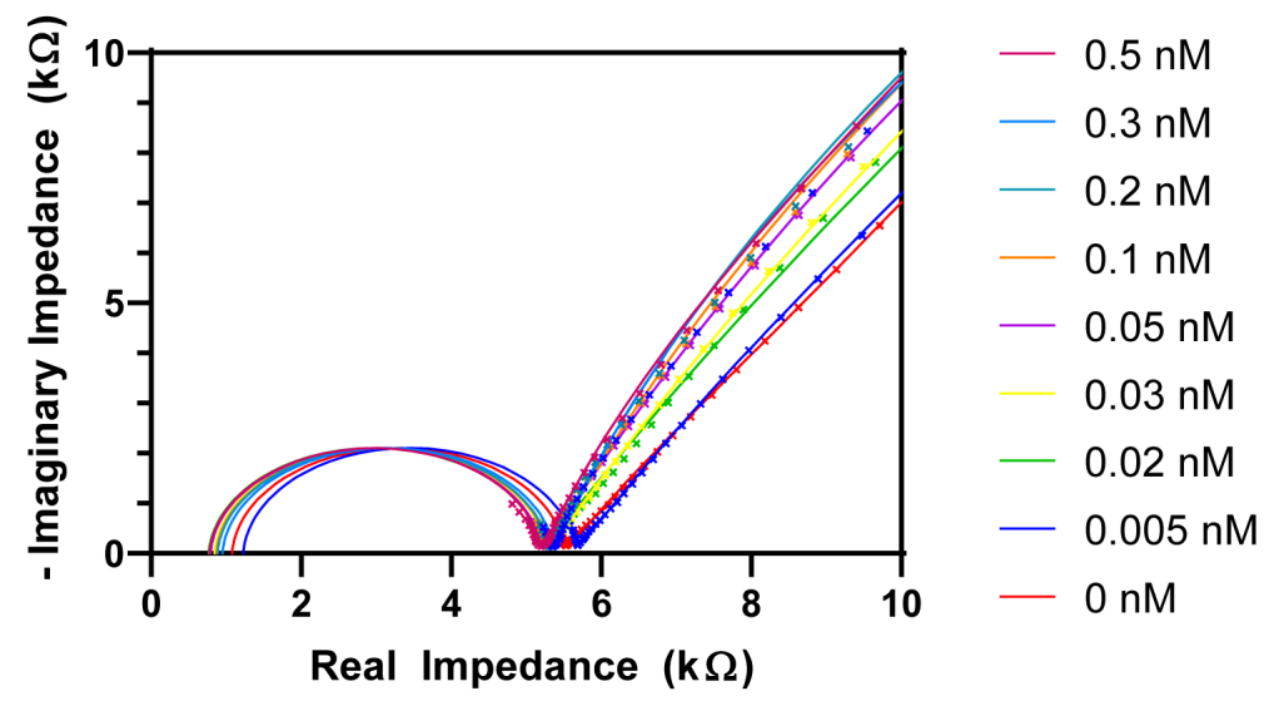

Figure S8. Zoomed in Nyquist plot that shows the actual and simulated data, for increasing concentration of PFOS, that were generated based on the fitting of the actual data to an equivalent circuit containing one resistor and three Randles Cells in Series. A MIP-modified glassy carbon macroelectrode, carbon rod, and $\mathrm{Ag} / \mathrm{AgCl}$ electrode were used as the working, counter, and reference electrode, respectively. 
Table S1. Details regarding the Brown-Forsythe and ANOVA tests between the response of a MIPmodified glassy carbon macroelectrode to $0 \mathrm{nM}, 0.2 \mathrm{nM}$, and $0.5 \mathrm{nM}$ PFOS in PBS using differential pulse voltammetry. $(\mathrm{P}=0.05, \mathrm{~N}=3$ individual electrodes)

\begin{tabular}{|l|r|}
\hline Brown-Forsythe ANOVA test & \\
\hline$F^{*}(\mathrm{DFn}, \mathrm{DFd})$ & $1.454(2.000,2.762)$ \\
\hline P value & 0.3704 \\
\hline P value summary & $\mathrm{ns}$ \\
\hline Significant diff. among means $(\mathrm{P}<0.05) ?$ & $\mathrm{No}$ \\
\hline Welch's ANOVA test & $\mathrm{ns}$ \\
\hline W (DFn, DFd) & No \\
\hline P value & $3.059(2.000,2.823)$ \\
\hline P value summary & 3 \\
\hline Significant diff. among means $(\mathrm{P}<0.05) ?$ & 9 \\
\hline Data summary & \\
\hline Number of treatments (columns) & \\
\hline Number of values (total) & \\
\hline
\end{tabular}


Table S2. Details regarding the Brown-Forsythe and ANOVA tests between the data points on the calibration curves made with a MIP-modified glassy carbon macroelectrode in PBS using differential pulse voltammetry. ( $\mathrm{P}=0.05, \mathrm{~N}=4$ individual sensors $)$

\begin{tabular}{|c|c|}
\hline Brown-Forsythe ANOVA test & \\
\hline $\mathrm{F}^{*}(\mathrm{DFn}, \mathrm{DFd})$ & $9.594(4.000,14.25)$ \\
\hline P value & 0.0006 \\
\hline $\mathrm{P}$ value summary & $* * *$ \\
\hline Significant diff. among means $(\mathrm{P}<0.05)$ ? & Yes \\
\hline \multicolumn{2}{|l|}{ Welch's ANOVA test } \\
\hline $\mathrm{W}(\mathrm{DFn}, \mathrm{DFd})$ & $8.511(4.000,7.478)$ \\
\hline $\mathrm{P}$ value & 0.0067 \\
\hline $\mathrm{P}$ value summary & $* *$ \\
\hline Significant diff. among means $(\mathrm{P}<0.05)$ ? & Yes \\
\hline \multicolumn{2}{|l|}{ Data summary } \\
\hline Number of treatments (columns) & 5 \\
\hline Number of values (total) & 20 \\
\hline
\end{tabular}


Table S3. Details regarding the Brown-Forsythe and ANOVA tests between the data points on the calibration curves made with a MIP-modified glassy carbon macroelectrode in Haw River Water using differential pulse voltammetry. $(\mathrm{P}=0.05, \mathrm{~N}=4$ individual sensors)

\begin{tabular}{|l|r|}
\hline Brown-Forsythe ANOVA test & \\
\hline$F^{*}(\mathrm{DFn}, \mathrm{DFd})$ & $47.62(4.000,9.632)$ \\
\hline P value & $<0.0001$ \\
\hline P value summary & *** \\
\hline Significant diff. among means $(\mathrm{P}<0.05) ?$ & \\
\hline Welch's ANOVA test & $<0.0001$ \\
\hline W (DFn, DFd) & $* * * *$ \\
\hline P value & Yes \\
\hline P value summary & $59.62(4.000,6.964)$ \\
\hline Significant diff. among means $(\mathrm{P}<0.05) ?$ & 5 \\
\hline Data summary & 20 \\
\hline Number of treatments (columns) & \\
\hline Number of values (total) & \\
\hline
\end{tabular}


Table S4. Details regarding the Brown-Forsythe and ANOVA tests between the data points on the calibration curves made with a MIP-modified glassy carbon macroelectrode in Haw River Water with electrochemical impedance spectroscopy. $(\mathrm{P}=0.05, \mathrm{~N}=3$ individual sensors $)$

\begin{tabular}{|l|r|}
\hline Brown-Forsythe ANOVA test & \\
\hline$F^{*}(\mathrm{DFn}, \mathrm{DFd})$ & $69.86(7.000,8.907)$ \\
\hline P value & $<0.0001$ \\
\hline P value summary & $* * * *$ \\
\hline Significant diff. among means $(\mathrm{P}<0.05) ?$ & Yes \\
\hline Welch's ANOVA test & $<0.0001$ \\
\hline W (DFn, DFd) & $* * * *$ \\
\hline P value & Yes \\
\hline P value summary & $89.25(7.000,6.798)$ \\
\hline Significant diff. among means $(\mathrm{P}<0.05) ?$ & 8 \\
\hline Data summary & 24 \\
\hline Number of treatments (columns) & \\
\hline Number of values (total) & \\
\hline
\end{tabular}


Table S5. Details regarding the Brown-Forsythe and ANOVA tests between the response of a MIP-modified glassy carbon macroelectrode to $0.07 \mathrm{nM}$ PFOS and $0.07 \mathrm{nM}$ PFOS + interferent (either humic acid or sodium chloride) in Haw River Water using electrochemical impedance spectroscopy. ( $\mathrm{P}=0.05, \mathrm{~N}=3$ individual sensors)

\begin{tabular}{|l|r|}
\hline Brown-Forsythe ANOVA test & \\
\hline$F^{*}(\mathrm{DFn}, \mathrm{DFd})$ & $0.9173(2.000,5.721)$ \\
\hline P value & 0.4513 \\
\hline P value summary & $\mathrm{ns}$ \\
\hline Significant diff. among means $(\mathrm{P}<0.05) ?$ & $\mathrm{No}$ \\
\hline Welch's ANOVA test & $\mathrm{ns}$ \\
\hline W (DFn, DFd) & $\mathrm{No}$ \\
\hline P value & $0.7555(2.000,3.956)$ \\
\hline P value summary & 3 \\
\hline Significant diff. among means $(\mathrm{P}<0.05) ?$ & 9 \\
\hline Data summary & \\
\hline Number of treatments (columns) & \\
\hline Number of values (total) & \\
\hline
\end{tabular}

